\title{
Changing demography and the challenge of dementia in India
}

\section{Vijayalakshmi Ravindranath $\mathbb{B}^{凶}$ and Jonas S. Sundarakumar}

Abstract | In India, increasing lifespan and decreasing fertility rates have resulted in a growing number of older persons. By 2050, people over 60 years of age are predicted to constitute $19.1 \%$ of the total population. This ageing of the population is expected to be accompanied by a dramatic increase in the prevalence of dementia. The aetiopathogenesis of dementia has been the subject of a number of prospective longitudinal studies in North America and Europe; however, the findings from these studies cannot simply be translated to the Indian population. The population of India is extremely diverse in terms of socio-economic, cultural, linguistic, geographical, lifestyle-related and genetic factors. Indeed, preliminary data from recently initiated longitudinal studies in India indicate that the prevalence of vascular and metabolic risk factors, as well as white matter hyperintensities, differs between urban and rural cohorts. More information on the complex role of vascular risk factors, gender and genetic influences on dementia prevalence and progression in Indian populations is urgently needed. Low-cost, culturally appropriate and scalable interventions need to be developed expeditiously and implemented through public health measures to reduce the growing burden of dementia. Here, we review the literature concerning dementia epidemiology and risk factors in the Indian population and discuss the future work that needs to be performed to put in place public health interventions to mitigate the burden of dementia.
Demographic pyramid A graphical representation of the age and gender distribution of a population at a particular point in time.
Dementia is a syndrome that presents as impairment of mental processes, such as memory, thinking, reasoning and judgement, and thus seriously impairs an individual's ability to perform functions of daily living. The syndrome is typically caused by a group of progressive, neurodegenerative brain disorders that occur in older age. The cost of care of people with dementia is enormous, at both the family and societal level. Therefore, it presents a substantial challenge, both in terms of public health and global economics ${ }^{1}$. According to WHO estimates, $\sim 50$ million people have dementia worldwide, with 10 million new diagnoses every year ${ }^{2}$. A number of prospective, longitudinal studies performed in North America and Europe have provided deeper insights into the aetiopathogenesis of dementia; however, similar studies in low-income and middle-income countries (LMICs), including South Asia (India, Pakistan, Afghanistan, Bangladesh, Nepal, Bhutan, Sri Lanka and Maldives), are lacking ${ }^{3,4}$. In the past, the burden of communicable diseases in South Asian countries was high; however, public health measures implemented over the last two decades have reduced this burden substantially. Increasing longevity and a growing prevalence of non-communicable diseases, such as diabetes, hypertension and cardiovascular disease, has resulted in an epidemiological transition from communicable to non-communicable diseases, which are now responsible for the majority of the overall disease burden in the region ${ }^{5-8}$.

As mentioned above, life expectancy has increased across South Asia (FIG. 1a). This increase in longevity can be observed in the growing percentage of the population who are over 65 years of age (FIG. 1 b). The decrease in fertility rates (FIC. 1c) that has been observed in South Asian countries has also contributed to an increase in the proportion of older individuals in the total population. In India, the proportion of persons aged 60 years and above is projected to be $19.1 \%$ - that is, around 316 million, or approximately the size of the current US population - in the year 2050 (REF. ${ }^{9}$ ). However, even within India, the shift in demography varies across states. For example, Kerala in southern India, which is moving towards a population growth rate of zero, has a larger proportion of older individuals than states such as Uttar Pradesh in northern India, in which the demographic pyramid is retained and only $8.6 \%$ of the population are over 60 years of age ${ }^{10}$. Dementia is one of the major contributors to disability in older people. Therefore, a rise in the number of older persons is expected to result in an increase in dementia burden. 


\section{Key points \\ - Increasing lifespan means that the incidence and prevalence of dementia in India is growing and is expected to rise dramatically in the coming decades. \\ - The Indian population currently has a very high burden of vascular risk factors, such as diabetes, hypertension and obesity, which can adversely impact the onset and progression of dementia. \\ - To identify risk and protective factors that contribute to dementia in India, longitudinal cohort studies need to be performed in urban and rural settings. \\ - These studies should include brain imaging, detailed genetic analysis and measurement of blood biomarkers, in addition to the use of well-adapted clinical and cognitive assessments. \\ - Evidence from studies performed outside of India indicate that dementia burden can be reduced through community-based, multimodal, early interventions, including dietary changes, increased physical activity and control of vascular risks; however, to be effective in India, interventions need to be adapted to the specific sociocultural milieu. \\ - Tools and data must be shared, both internationally and within the resource- constrained low-income and middle-income countries, to drive research towards better interventions to reduce the burden of dementia.}

The WHO estimates that the global number of individuals with dementia will increase from the current 50 million to 82 million in 2030 and 152 million in 2050 (REF.). Owing to the size of its population, South Asia, especially India, will be a major contributor to this increase ${ }^{11}$.

Cardiovascular risk factors, such as diabetes and hypertension, also have an effect on cerebral vasculature, which in turn, can increase the risk of stroke and dementia ${ }^{12}$. According to the Diabetes Atlas, published by the International Diabetes Federation in $2019^{13}$, India has the second-highest number of people with diabetes in the world and the South Asian region is one of the epicentres of the diabetes epidemic. India is home to $77 \mathrm{mil}-$ lion adults (20-79 years of age) with diabetes. Recent data from the National Family Health Survey 5 (NFHS 5 , 2019-2020 $)^{14}$, a nationally representative household survey from across India, show an alarmingly high prevalence of elevated blood glucose levels. An increasing prevalence of hypertension has also been observed in India ${ }^{15}$. Indeed, in 2014 a meta-analysis ${ }^{16}$ estimated that in India, $\sim 33 \%$ of individuals living in urban settings, and $25 \%$ of individuals living in rural settings, are hypertensive. Both diabetes and hypertension are under-diagnosed and under-treated, particularly in rural India ${ }^{17-19}$. Furthermore, cardiovascular diseases have been ranked among the leading contributors to death and disability in India, and it is predicted that the burden of these diseases will continue to increase in the coming decades ${ }^{20}$. The estimated percentage of deaths resulting from cardiovascular diseases in India has risen from $14.5 \%$ in 1990 to $27.4 \%$ in 2019 (REF. ${ }^{21}$ ). Reasons for the above trends could include changes in lifestyle (especially dietary patterns), rapid urbanization, sedentary work environments and increased environmental pollution.

The tremendous diversity that exists within the South Asian countries in terms of language, socio-economic background and genetics makes studying the ageing population complicated. For example, India is a uniquely diverse nation comprising 28 states, which differ substantially in geography, population density, genetic origin and culture. In this sense, India's sociodemographic landscape is a good representation of the diversity of the South Asian region in general. In addition, a vast disparity exists between urban middle-class individuals in India and those who live in rural areas. This disparity includes differences in socio-economic status, lifestyle and literacy, as well as access to health care and the internet. According to national data for 2017-2018, substantial differences in literacy levels exist between urban $(87.7 \%)$ and rural areas $(73.5 \%)$, between different states (96.2\% in Kerala compared with $66.4 \%$ in Andhra Pradesh), and between men (84.7\%) and women $(70.3 \%)^{22}$.

Here, we review current knowledge of dementia in India and describe the potential challenges that the country will face in the coming decades as a result of the increasing dementia burden. We also highlight important areas for future research, including the identification of risk and protective factors that influence the prevalence of dementia in India. This knowledge will be essential for the development of appropriate public health strategies to mitigate the enormous burden of this emerging public health concern.

\section{Prevalence of dementia in India}

The Global Burden of Disease Study estimated that, in 2016, 3.74 million people in South Asia had dementia, including 2.93 million people from India (total population 1.36 billion), whereas an estimated 4.02 million people had dementia in the USA (total population 322.87 million $)^{23}$. The estimate for the USA was based on several large, epidemiological studies; however, the estimate for India was extrapolated from the sparse available data. Thus, rigorous, large-scale epidemiological studies on dementia prevalence in India are still required. Dementia research in India also poses unique challenges such as the need to adapt cognitive tests (most of which were originally developed in English-speaking countries for literate individuals) to the sociocultural context ${ }^{24}$, while taking into account the fact that large sections of population have low levels of literacy. Although some cognitive tests, such as the Addenbrooke's Cognitive Examination (ACE-III), have been translated and adapted to Indian languages ${ }^{25}$, the relevance of such tests among illiterate populations is a matter for debate. A neurocognitive test battery called the Indian Council of Medical Research-Neurocognitive Tool Box (ICMR-NCTB) was developed in India for use among literate and illiterate individuals ${ }^{26}$.

Studies conducted in India from 1996 to 2017 showed variations in dementia prevalence across the country (FIG. 2; TABLE 1). A collaborative India-USA study ${ }^{27}$ was conducted in 1996 in the rural area of Ballabgarh in the state of Haryana in northern India. In this study, 5,126 individuals aged 55 years and older underwent cognitive and functional screening, including the Hindi Mental State Examination (HMSE) - the Indian adaptation of the Mini Mental State Examination (MMSE). Participants $(n=536)$ who were deemed to have cognitive impairment on the basis of this screening underwent further clinical diagnostic assessment for dementia according to the Diagnostic and Statistical Manual, 4th edition (DSM-IV) and staging of dementia using the 
Clinical Dementia Rating (CDR). The overall prevalence of all dementias with a CDR score of $\geq 0.5$ was $0.8 \%$ (95\% CI $0.6-1.1 \%$ ) in individuals $\geq 55$ years of age and $1.3 \%$ (95\% CI $0.9-1.8 \%$ ) in individuals $\geq 65$ years of age. A subsequent study found a higher dementia prevalence of up to $10.6 \%(95 \% \text { CI } 8.6-12.6 \%)^{28}$ in individuals aged $\geq 65$ years in rural Vellore in southern India.

The 10/66 Dementia Research Group investigated the prevalence and severity of dementia and did a comparative analysis across 11 sites in seven LMICs (India, China, Cuba, Dominican Republic, Venezuela, Mexico and Peru), including two sites in India (a rural site in Vellore and an urban site in Chennai, both in the southern state of Tamil Nadu) ${ }^{28}$. The study used two different criteria for the diagnosis of dementia, namely, the 10/66 dementia diagnosis algorithm and the DSM-IV diagnostic criteria. The 10/66 algorithm is a tool that was developed especially for the diagnosis of dementia in populations with low levels of education in LMICs and has a sensitivity of $94 \%$ and a specificity of $97 \%$ in individuals with a high level of education; specificity drops to $94 \%$ in individuals with low levels of education ${ }^{29}$. Using the 10/66 algorithm, estimated dementia prevalence in individuals aged $>65$ years was $7.5 \%$ (95\% CI $5.8-9.1 \%)$ in the rural site (Vellore) and $10.6 \%$ (95\% CI 8.6-12.6\%) in the urban site (Chennai). In contrast, using the DSM-IV criteria, prevalence was estimated at $0.9 \%(95 \% \mathrm{CI} 0.3-1.5 \%)$ in the rural site and $0.8 \%$ (95\% CI $0.2-1.3 \%)$ in the urban site. The wide variation in the estimated prevalence highlights the importance of the diagnostic tools used to assess dementia ${ }^{28}$.

A cross-sectional study ${ }^{30}$ estimated the prevalence of major neurological disorders, including dementia, in a sample of 52,377 participants from Kolkata. The study population was selected using a stratified random sampling method and individuals with dementia were identified using a two-stage assessment methodology (cognitive screening followed by clinical diagnosis based on DSM-IV criteria). Dementia prevalence was $1.0 \%$ in individuals aged $\geq 60$ years. The same group of researchers conducted a longitudinal dementia survey $(n=100,802)^{31}$ in the same geographical area and estimated the yearly dementia prevalence to be $1.5 \%$ in individuals aged $\geq 65$ years. In another study, no cases of dementia were diagnosed among 500 individuals aged $>60$ years living in the Himalayan region ${ }^{32}$.

In conclusion, the results discussed above indicate that the prevalence of dementia in India can be up to $10.6 \%$, with variations across different states ${ }^{27,28}$ as well as within the same region ${ }^{28,33,34}$. Although this variation could be attributed to the wide variation in demography (for example, the demographic differences between the states of Kerala and Uttar Pradesh mentioned above), it could also be attributed to the different sampling methods or diagnostic tools used, particularly as these tools are adapted to the local sociocultural environment. Functional impairment is an important criterion in the diagnosis of dementia using DSM-IV or the International Classification of Diseases (ICD). This impairment varies depending on sociocultural environment ${ }^{35}$ and might have contributed to the wide variation in reported prevalence. According to the
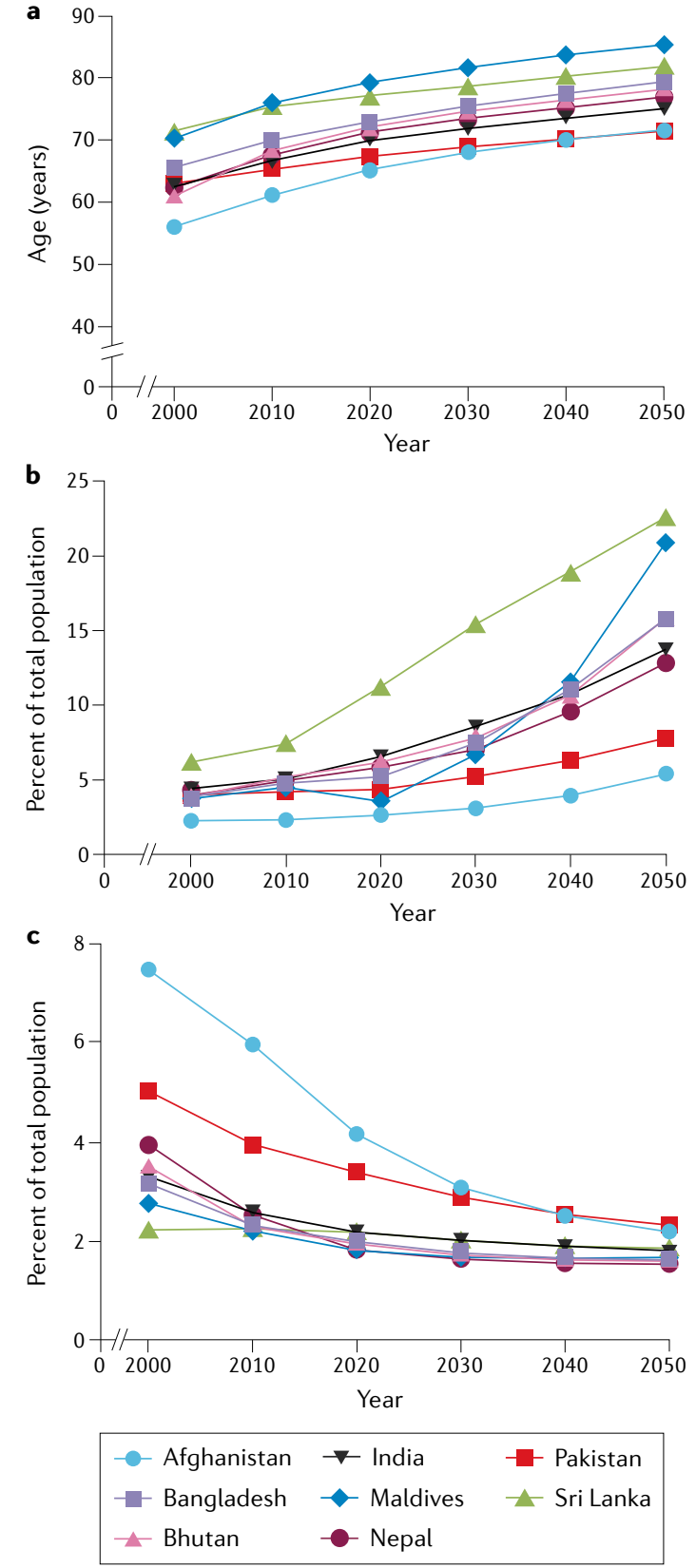

Fig. 1 | Changing demographic trends in the South Asian region. a | Average life expectancy at birth for eight South Asian countries from 2000, including projections for 2020, 2030, 2040 and 2050. b | Percentage of the population $\geq 65$ years of age. $c \mid$ Total fertility rate. Data from https://data.worldbank.org/.

Dementia in India 2020 report $^{36}$ an estimated 5.3 million Indians aged $>60$ years had dementia in 2020 , and this number is projected to exceed 14 million by 2050 .

\section{Dementia risk factors in India}

We now know that the changes in the brain that eventually lead to dementia start at least two decades before the presentation of overt clinical symptoms $\mathrm{s}^{37}$. In addition, imaging and post-mortem studies have led to the understanding that there are multiple factors, including accumulation of amyloidogenic proteins in the brain, 
cerebrovascular dysfunction and loss of grey matter that, acting collectively, lead to dementia. Indeed, the most prevalent form of dementia is mixed dementia, which includes a substantial contribution from vascular dysfunction, particularly cerebral small-vessel disease ${ }^{38-40}$.

\section{Vascular risk factors}

Risk factors for vascular dysfunction confer the risk of cerebrovascular dysfunction and can thereby contribute to dementia ${ }^{41,42}$. Large-vessel strokes are prevalent in India and the prevalence of risk factors for vascular dysfunction - that is, diabetes, hypertension, dyslipidaemia, obesity and tobacco use - has increased substantially in the last two to three decades ${ }^{43}$. This increase is reflected in the rates of mortality and morbidity from cardiovascular disease, which have increased from 140.4 per 100,000 deaths (ranked third) and 4111.1 per 100,000 disability-adjusted life-years (DALYs; ranked fifth) in 1990 to 185.2 per 100,000 deaths (ranked first) and 4670.0 per 100,000 DALYs (ranked first) in 2019 (REF. ${ }^{21}$ ) (FIG. 3). Indeed, in 1990, the major contributors to morbidity in India were child wasting, low birthweight and short gestation but, by 2020 , the major contributors were high systolic blood pressure, smoking and high fasting glucose. Cerebrovascular disease burden also increased over this period - the percentage of deaths from stroke in India rose from 4.5\% in 1990 to $7.4 \%$ in 2019 (REF. ${ }^{21}$ ). This trend is in sharp contrast to that in Western countries, where lifestyle intervention measures have resulted in decreased stroke mortality ${ }^{21}$.

The Longitudinal Aging Study in India-Diagnostic Assessment of Dementia (LASI-DAD) is an ongoing study that aims to assess late-life cognition and a range of other health and lifestyle factors in participants $(n=3,224)$ from 14 states in both urban and rural India ${ }^{44}$. The LASI-DAD is a substudy within a large, nationally representative survey of the health, economic and social well-being of the Indian population aged $\geq 45$ years. Although the LASI-DAD is still ongoing, preliminary baseline data from the study have been published ${ }^{45}$ and indicate that nearly two-thirds of older Indians have hypertension (self-reported or measured blood pressure of $140 / 90 \mathrm{mmHg}$ or higher), with the majority being undiagnosed or diagnosed but not adequately controlled ${ }^{45}$. Importantly, routine screening of blood pressure is not yet practised in India, so the self-reported measures could grossly underestimate the prevalence of hypertension. In the LASI-DAD data, hypertension was not independently associated with cognitive function; however, older age, low education, rural residence, low BMI and a history of stroke were inversely associated with total cognitive score ${ }^{46}$. When compared with data from its sister study in the USA - the Harmonized Cognitive Assessment Protocol of the Health and Retirement Study (HRS-HCAP) - the prevalence of most cardiometabolic and inflammatory risk factors was higher in the LASI-DAD cohort ${ }^{46}$. This finding is in agreement with a previous study that identified a higher prevalence of cardiovascular disease in India than in the $\mathrm{USA}^{47}$. Furthermore, the LASI-DAD data indicate that higher BMI and glycosylated haemoglobin levels (indicative of hyperglycaemia) are associated with better performance in cognitive tests in the Indian population ${ }^{46}$. This finding is contrary to the results of a study in the USA that identified a higher burden of AD neuropathology in individuals with higher BMI in midlife ${ }^{48}$. Similarly, in a

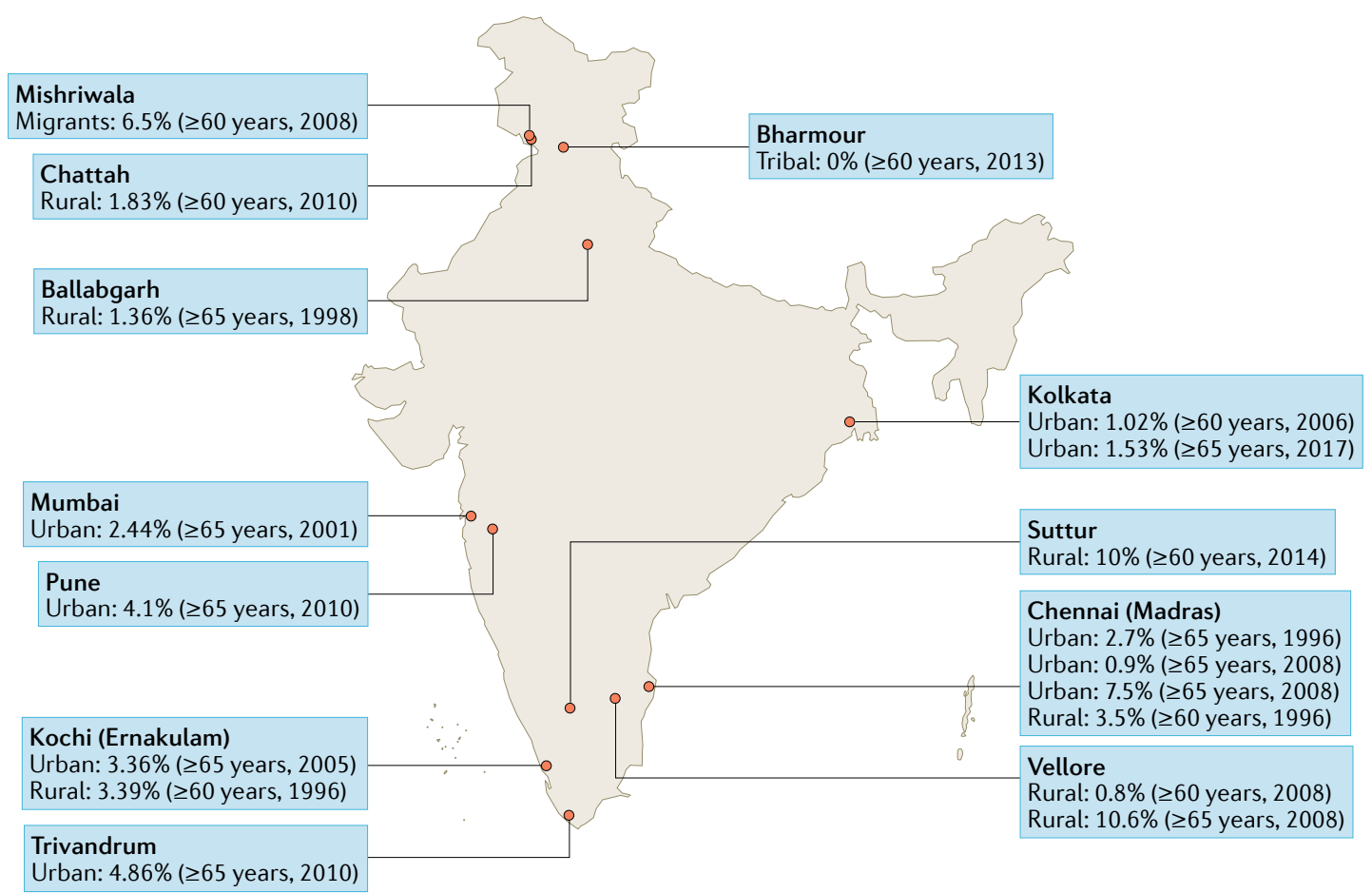

Fig. 2 | Varying prevalence of dementia according to geographical location in India. This figure shows the prevalence of dementia in different geographical locations in India. Also provided is the age range of the population studied and the year of publication. 
Table 1 | Studies of dementia prevalence in India published since 1996

\begin{tabular}{|c|c|c|c|c|c|c|}
\hline \multirow[t]{2}{*}{ Study } & \multirow[t]{2}{*}{ Place } & \multirow{2}{*}{$\begin{array}{l}\text { Number of } \\
\text { participants }\end{array}$} & \multirow{2}{*}{$\begin{array}{l}\text { Age } \\
\text { (years) }\end{array}$} & \multirow[t]{2}{*}{ Assessment tools } & \multicolumn{2}{|c|}{ Prevalence } \\
\hline & & & & & $\%$ & Age (years) \\
\hline \multicolumn{7}{|l|}{ Rural setting } \\
\hline \multirow{2}{*}{ Shaji et al. $(1996)^{124}$} & \multirow{2}{*}{ Ernakulam } & \multirow{2}{*}{2,067} & \multirow{2}{*}{$\geq 60$} & Phase 2: CAMDEX sections $\mathrm{B}, \mathrm{H}$ (adapted version) & \multirow{2}{*}{3.39} & \multirow{2}{*}{$\geq 60$} \\
\hline & & & & Phase 3: DSM-IIIR & & \\
\hline \multirow[t]{2}{*}{ Chandra et al. $(1998)^{27}$} & \multirow[t]{2}{*}{ Ballabgarh } & \multirow[t]{2}{*}{5,126} & \multirow[t]{2}{*}{$\geq 55$} & Phase 1: Cognitive and functional screening & $0.84^{\mathrm{a}}$ & $\geq 55$ \\
\hline & & & & Phase 2: DSM-IV & $1.36^{\mathrm{a}}$ & $\geq 65$ \\
\hline \multirow[t]{2}{*}{ Rodriguez et al. $(2008)^{28}$} & \multirow[t]{2}{*}{ Vellore } & \multirow[t]{2}{*}{999} & $\geq 65$ & Single phase: DSM-IV, CDR & 0.8 & $\geq 65$ \\
\hline & & & & Single phase: $10 / 66$ algorithm, CDR & 10.6 & $\geq 65$ \\
\hline Raina et al. $(2010)^{126}$ & Chattah & 1,856 & $\geq 60$ & Phase 1: MMSE (adapted), EASI & 1.83 & $\geq 60$ \\
\hline & & & & Phase 2: Clinical diagnosis & & \\
\hline Raina et al. $(2013)^{32}$ & Bharmour ${ }^{c}$ & 500 & $\geq 60$ & Phase 1: MMSE (adapted), EASI & 0 & $\geq 60$ \\
\hline & & & & Phase 2: Clinical diagnosis & & \\
\hline Rao et al. $(2014)^{127}$ & Suttur & 3,033 & All ages & Single phase: DSM-IV-TR and ICD-10 & 0.9 & $\geq 40$ \\
\hline & & & & & 10 & $\geq 60$ \\
\hline Urban setting & & & & & & \\
\hline Rajkumar and Kumar & Madras & 1,300 & $\geq 65$ & Phase 1: GMS-AGECAT & 2.7 & $\geq 65$ \\
\hline & & & & Phase 2: ICD-10 & & \\
\hline Das et al. $(2006)^{30}$ & Kolkata & 52,377 & All ages & Phase 1: NIMHANS screening questionnaire and & 0.48 & $\geq 50$ \\
\hline & & & & $\begin{array}{l}\text { adapted cognitive screening battery, including HMSE } \\
\text { Phase 2: DSM-IV }\end{array}$ & 1.02 & $\geq 60$ \\
\hline Rodriguez et al. $(2008)^{28}$ & Chennai & 1,005 & $\geq 65$ & Single phase: DSM-IV, CDR & 0.9 & $\geq 65$ \\
\hline & & & & Single phase: $10 / 66$ algorithm, CDR & 7.5 & $\geq 65$ \\
\hline Mathuranath $(2010)^{130}$ & Trivandrum & 2,466 & $\geq 55$ & Phase I: IADL-E and ACE (Malayalam) & 3.77 & $\geq 55$ \\
\hline & & & & Phase II: DSM-IV & 4.86 & $\geq 65$ \\
\hline Saldanha et al. $(2010)^{131}$ & Pune & 2,145 & $\geq 65$ & Phase 1: CSI 'D', CERAD, MMSE & 4.1 & $\geq 65$ \\
\hline & & & & Phase 2: ICD-10 & & \\
\hline Banerjee et al. $(2017)^{31}$ & Kolkata & 100,802 & $\geq 55$ & Phase 1: KCSB, EASI & 1.53 & $\geq 65$ \\
\hline & & & & Phase 2: DSM-IV, CDR & & \\
\hline
\end{tabular}

ACE, Addenbrooke's Cognitive Examination; ADL, Activities of Daily Living; CAMDEX, Cambridge Mental Disorders of the Elderly Examination; CDR, Clinical Dementia Rating; CERAD, Consortium to Establish a Registry for Alzheimer's Disease battery; CSI 'D'. Community Screening Instrument for Dementia; DSM, Diagnostic and Statistical Manual of Mental Disorders; EASI, Everyday Abilities Scale for India; GMS-AGECAT, Geriatric Mental State-Automated Geriatric Examination Computer-Assisted Taxonomy; HMSE, Hindi Mental State Examination; IADL-E, Instrumental Activities of Daily Living for the elderly; ICD, International Classification of Diseases; KCSB, Kolkata Cognitive Screening Battery; MMSE, Mini Mental State Examination; NIMHANS, National Institute of Mental Health and Neurosciences; SCAG, Sandoz Clinical Assessment-Geriatric. ${ }^{\mathrm{a} C D R}$ score $\geq 0.5$. ${ }^{\mathrm{b}}$ Migrant camp. ${ }^{\mathrm{C} T r i b a l .}$

10-year follow-up from the English Longitudinal Study of Ageing (ELSA), significant positive associations between haemoglobin $A_{1 c}$ levels, diabetic status and cognitive decline were identified ${ }^{49}$.
The role of cardiovascular risk factors in dementia has been studied in India ${ }^{50}$; however, the extent to which these factors affect cerebrovascular function is still not clear. Indeed, one possibility is that some risk factors 

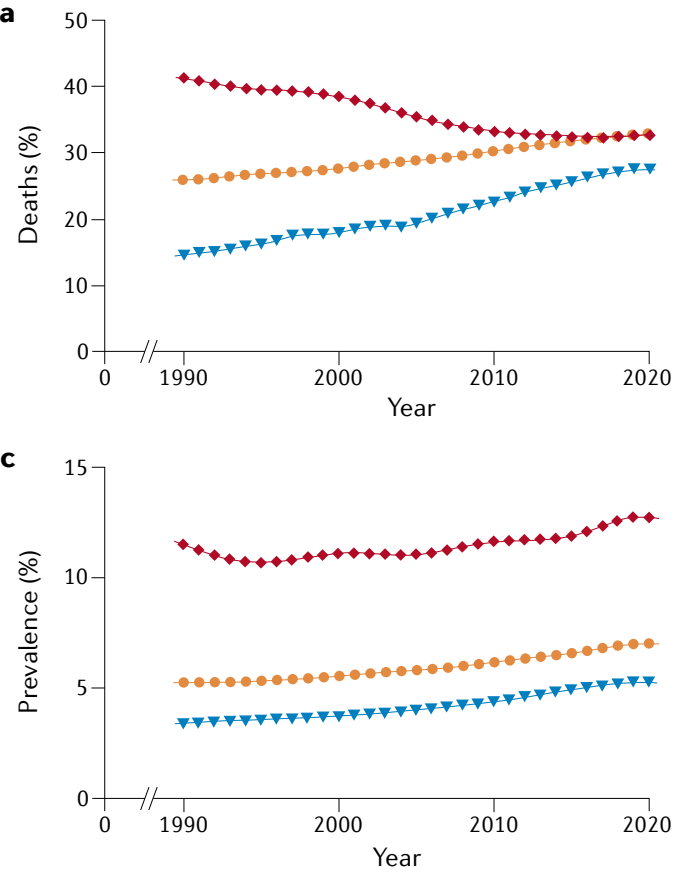

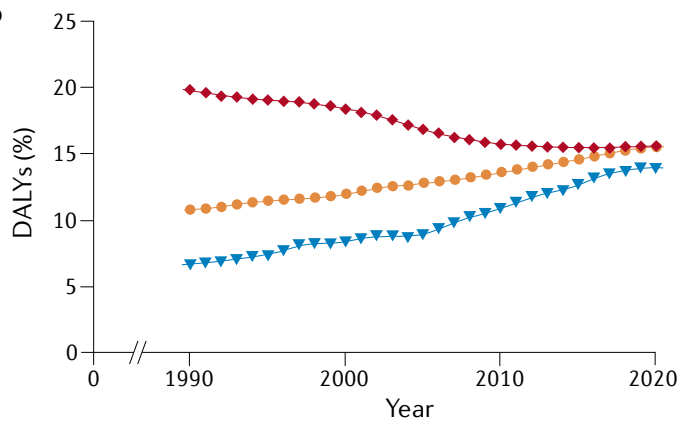

d

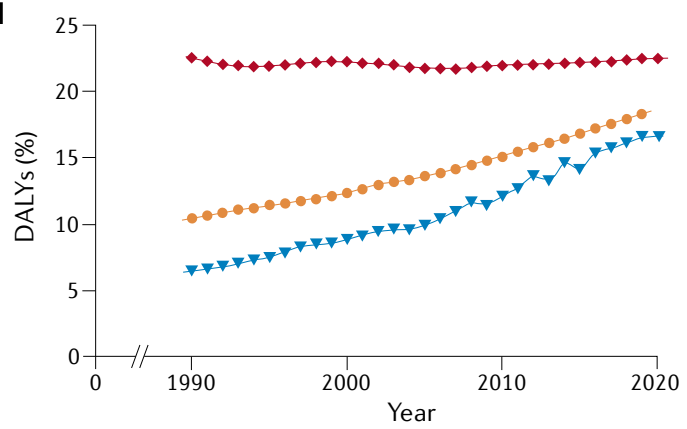

- Global $\rightarrow$ India $\bullet$ USA

Fig. 3 | Increasing burden of cardiovascular diseases and metabolic risk factors in India. a | Deaths caused by cardiovascular disease as a percentage of total deaths. b| Percentage of total disability-adjusted life years (DALYs) resulting from cardiovascular disease. $\mathbf{c}$ |Prevalence of cardiovascular disease. $\mathbf{d} \mid$ Percentage of total DALYs resulting from metabolic risk factors such as diabetes, hypertension and obesity. These data come from the Global Burden of Disease study. Adapted from: https://vizhub.healthdata.org/gbd-compare/.

have a different threshold for their effect on the brain compared with their effect on the heart, although this hypothesis is yet to be tested. In rural parts of India, women, in particular, are exposed to high levels of household air pollution resulting from the use of solid cooking fuels. Ambient air pollution in urban parts of India is also rapidly increasing, suggesting that compromised pulmonary function could contribute to vascular risk ${ }^{51-53}$.

\section{Genetic risk factors}

Apolipoprotein E. The presence of the $\varepsilon 4$ allele of the gene encoding apolipoprotein $\mathrm{E}(A P O E)$ is one of the major risk factors for Alzheimer disease (AD $)^{54}$. The relationship between $A P O E$ polymorphism and the prevalence of $A D$ in India was first studied as part of a collaborative India-USA project that compared participants recruited at a site in India (Ballabgarh) with those recruited at a parallel site in the USA (Monongahela Valley) ${ }^{55}$. The results of the study, performed by Ganguli and colleagues, indicated that the frequency of $A P O E \varepsilon 4$ in participants from Ballabgarh was one of the lowest in the world (0.07) and consistent with the very low prevalence of $\mathrm{AD}(0.62 \%$; $\mathrm{CDR}$ score $\geq 0.5)$ in this sample aged $\geq 55$ years. Although APOE $\varepsilon 4$ frequency in Ballabgarh was significantly lower than that in Monongahela Valley, the strength of the association between APOE $\varepsilon 4$ and $\mathrm{AD}$ was similar in both samples. In a study from southern India ${ }^{56}, A P O E \varepsilon 4$ frequency among participants with $\mathrm{AD}(n=137)$ was 0.21 , whereas a frequency of 0.08 was observed among healthy controls $(n=195)$. Other studies have found $A P O E \varepsilon 4$ frequencies in individuals with
$\mathrm{AD}$ ranging from 0.19 to $0.43\left(\mathrm{REFS}^{57-59}\right)$. Pandey and colleagues performed a genetic study in 107 participants with AD and 167 age-matched and gender-matched controls from northern India ${ }^{60}$. A significant association was observed between $A P O E \varepsilon 4$ allele frequency and increased risks of both degenerative and vascular dementias.

Other genetic risk factors. Presenilin 1 (PS1) is a part of the $\gamma$-secretase complex, which cleaves amyloid- $\beta$ (A $\beta)$ precursor protein to generate $A \beta_{1-42}$ peptide, which is causatively linked to AD. Some of the above $A P O E$ $\varepsilon 4$ studies also assessed the frequency of PS1 intron 8 polymorphisms. Pandey et al. identified a significant association between PS1 intron 8 polymorphism and degenerative dementias but not vascular dementias ${ }^{60}$. Conversely, Chandak et al. found a high frequency of allele 1 at presenillin 1 intron 8 polymorphism, but no significant association with the risk of $\mathrm{AD}^{57}$. Variants in the gene encoding low-density lipoprotein receptor-related protein-associated protein (LRPAP) are associated with late-onset $\mathrm{AD}^{61}$. In a study performed in northern India, the frequency of the DD genotype and the ${ }^{\star} \mathrm{D}$ allele of the gene encoding LRPAP was higher in degenerative dementias than in controls, although this trend was not statistically significant for the vascular dementias ${ }^{62}$. Other, smaller, genetic studies performed in India have implicated additional genes - including those encoding IL-6 (REF. ${ }^{63}$ ), glutathione $S$-transferase T1 $\left(\mathrm{REF}^{64}\right)$, paraoxonase $1\left(\mathrm{REF}^{65}\right)$ and microtubule-associated protein tau $^{66}-$ in dementia risk. 


\section{Gender differences}

Data from North America and Europe show a greater prevalence of dementia among women than among men $^{67,68}$. This disparity has often been attributed to the longer lifespan of women. Conversely, data from animal models indicates that oestrogen can have a neuroprotective effect ${ }^{69,70}$. There is a lack of data from India to indicate a differential incidence or prevalence of dementia between men and women, although the prevalence of most vascular risk factors is significantly higher among men than among women ${ }^{71,72}$. Nevertheless, from childhood onwards, women in India face tremendous challenges that could adversely affect brain health. Marked gender differences in childhood nutrition, immunization and morbidity put women at a disadvantage from early life $\mathrm{e}^{73}$. Furthermore, in a large study of Indian children with undernutrition, three of the top five predictors of childhood stunting and/or underweight status were maternal-related factors, that is, short maternal stature, mothers having no education and maternal underweight status $^{74}$. This finding indicates that the disadvantages faced by women have negative consequences on their offspring, setting off a damaging cascade of events.

A gross disparity in educational attainment also exists between women and men in India. According to the 2011 census, only $40.3 \%$ of women $>25$ years of age had completed primary school education, compared with $62.2 \%$ of men in the same age group ${ }^{10}$. In the LASI-DAD study, cognitive testing of individuals aged $>60$ years was performed at sites across 14 Indian states ${ }^{75}$. The study found that women performed significantly worse than men across most cognitive domains. A large percentage of this disparity was explained by differences in education levels and, to a lesser extent, childhood nutrition; early-life socio-economic factors also contributed to a small extent. Taken together, these findings suggest that poor health and nutritional status, coupled with lower educational attainment and social disadvantages, could adversely affect the brain health and cognitive ability of women as they age. The above conclusion underscores the need for targeted public health interventions for women throughout the life course, starting from childhood, to reduce the burden of dementia and comorbidities. Of note, gender is neither binary nor fixed; the discussion of 'men' and 'women' here is not meant to obscure that point.

\section{Other risk factors}

Data from North America and Europe indicate that life course events, particularly, social inequalities in early life or mid-life could be associated with poorer cognitive function $^{76-79}$ as well as frailty ${ }^{80}$ and multimorbidity ${ }^{81,82}$ in later life. Specifically, data indicate that lower levels of literacy and socio-economic status are associated with a higher risk of dementia, and that bilingualism or multilingualism could be considered a protective factor ${ }^{83,84}$. However, the impact of these factors in India, which includes several pockets of multilingualism and has an entirely different sociocultural milieu to North America and Europe, is not well understood. A cross-sectional study from central India found that the onset of $\mathrm{AD}$ dementia was delayed by 5 years and frontotemporal dementia by 3 years in people who are bilingual compared with people who are monolingual ${ }^{85,86}$. The protective effect of multilingualism remained after controlling for education. However, whether the ability to understand and speak more than one language, and use them in daily living, can overcome the disadvantage of low levels of literacy remains to be seen. Another factor that could contribute to an increasing prevalence of dementia in India is the change in the social environment caused by ongoing transition from the joint family system (three generations living together) to nuclear families, which results in less cognitive engagement for the elderly ${ }^{87}$.

Nutritional deficiencies, which are prominent in LMICs including India, could have an important role in the pathogenesis of dementia. Hyperhomocysteinaemia is a major risk factor for infarcts, including stroke. Deficiencies in vitamin $B_{12}$ and folic acid result in increased homocysteine, and studies performed in India found that vitamin $B_{12}$ deficiency and hyperhomocysteinaemia are associated with vascular risk factors in individuals with coronary artery disease ${ }^{88}$. In another study, higher plasma homocysteine levels were associated with a higher risk of dementia ${ }^{89}$. Evidence also indicates an association between vitamin D deficiency and poorer $\operatorname{cognition}^{90}$. Although India is a tropical country, two studies, both published in 2018 , found a high prevalence of vitamin D deficiency among individuals aged $\geq 18$ years and $\geq 60$ years at two sites in India ${ }^{91,92}$. The ongoing COVID-19 pandemic has severely restricted the outdoor movements of older people and is likely to have had an adverse impact on their vitamin D status. A detailed understanding of the associations between such deficiencies and cognitive impairment could help the development of public health measures to decrease dementia burden. For example, universal food fortification is much less prevalent in India than in the USA and Europe, with the exception of iodization of salt, which has successfully reduced the prevalence of iodine deficiency disorders. Similar strategies, such as fortification of milk with vitamin D could be adopted as a cost-effective public health intervention to reduce dementia risk. The factors influencing dementia prevalence in India are summarized in FIG. 4.

\section{Next steps}

India's diverse landscape can be visualized in two broad categories $^{93}$. Urban India consists of the urban poor (including migrant workers from villages), who generally have low levels of literacy, and the middle class, who generally have high levels of literacy and better access to health-care services ${ }^{94}$. Rural India consists of a predominantly agriculture-dependent population living in villages and hailing from a lower socio-economic background than the urban Indian population. The population of rural India also has low levels of literacy and compromised access to health-care services ${ }^{95}$. The urban poor in India are emerging as a distinct group who have experienced a rapid change in lifestyle, including a reduction in physical activity and a dramatic shift from a whole grain, fibre-rich diet to a diet of processed foods ${ }^{96}$. Given this scenario, conducting longitudinal studies from both urban and rural India is essential 


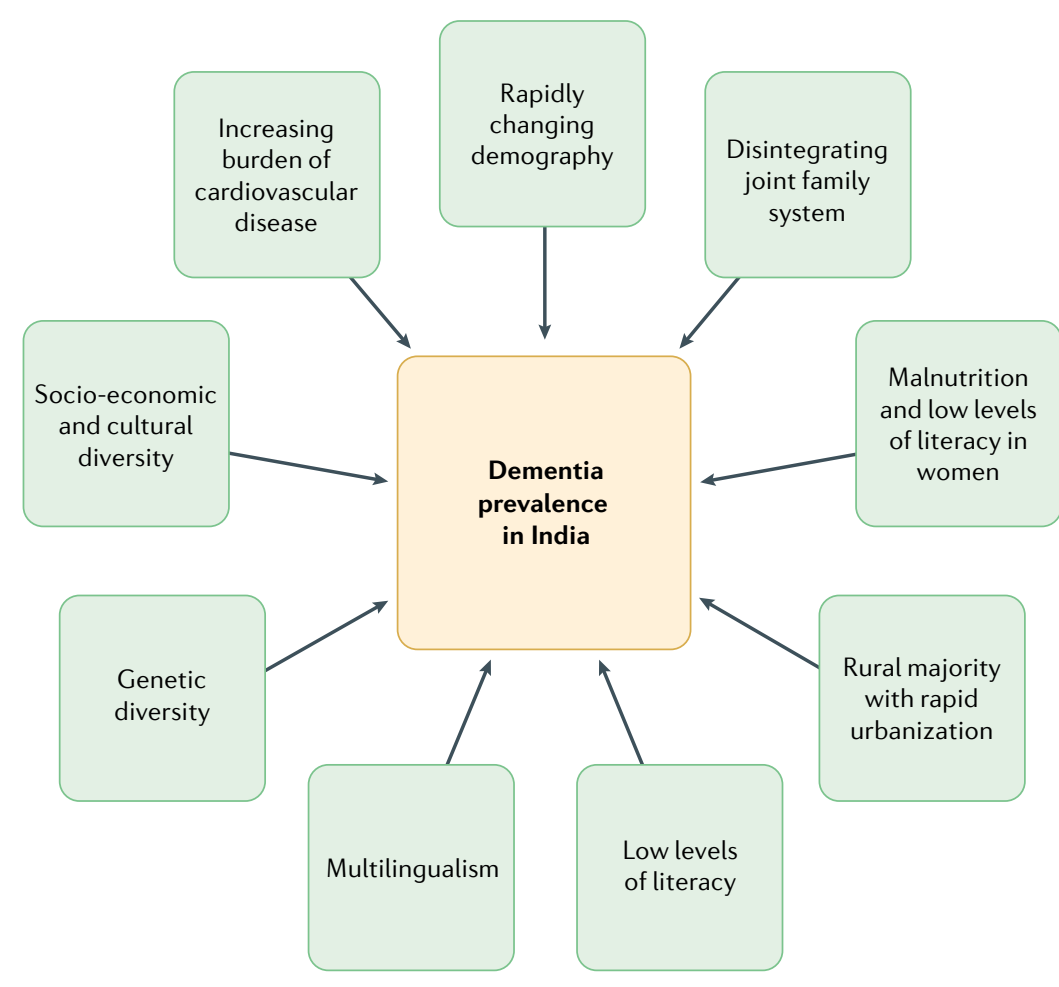

Fig. 4 | Factors that influence dementia prevalence in India. Although factors such as changing demography, increasing cardiovascular burden, low levels of literacy and disadvantages in women are common to many low-income and middle-income countries, the vast sociocultural and genetic diversity and disintegrating joint family system are unique to India. agricultural community (projected $n=10,000$ ). These individuals are generally bilingual ( $>85 \%$ ), are unlikely to have migrated from other parts of India, have low levels of education and belong to a lower socio-economic stratum than the TLSA participants. SANSCOG participants undergo multimodal, comprehensive assessments (clinical, cognitive, biochemical, genetic and neuroimaging) that have been harmonized with TLSA. This harmonization provides a unique opportunity for head-to-head comparisons of outcome measures between these two cohorts. The cognitive test battery covering attention, memory, visuospatial processing and language (COGNITO) ${ }^{99}$ used in both these studies has been adapted to the local sociocultural milieu and the low levels of literacy in the rural cohort.

According to preliminary data from baseline assessments in the two studies, the prevalence of vascular risk factors such as, hypertension, diabetes, obesity and dyslipidaemia were lower in the rural cohort (SANSCOG) than in the urban cohort (TLSA) ${ }^{100}$; however, nutritional deficiencies were much higher in the rural cohort than in the urban cohort. In individuals aged 45-54 years, the frequency and volume of white matter hyperintensity, assessed using MRI, were greater in the rural cohort than the urban cohort ${ }^{101}$. These findings were presented at the Alzheimer Association International Conference in 2020 but have not yet been published in a peer-reviewed journal. The two studies are also still in the early stages, so larger sample sizes and longitudinal data will be required to confirm these observations.

Another multicentre cohort study - Advancing Approaches for Dementia and Associated Research (AADAR) - is planned with the aim of determining the burden and risk factors for dementia in India ${ }^{102}$. This study will involve three populations: one from rural northern India, one a tribal population from north-eastern India, and one an urban population from southern India. The researchers plan to follow-up the cohort for 9 years with the goal of identifying risk and protective factors.

The Tata Longitudinal Study on Aging (TLSA) is a ongoing, prospective, community-based, cohort study in India that was started in 2015. The goal of the study is to build a cohort (projected $n=1,000$ ) of ageing individuals for longitudinal follow-up to identify risk and protective factors for cognitive decline and $\mathrm{AD}^{97}$. The cohort comprises cognitively healthy individuals of all genders aged $\geq 45$ years. The participants are recruited from urban Bangalore, a large metropolitan city in the state of Karnataka in southern India. In general, these participants are well-educated, majorly multilingual and have migrated from other parts of India. Detailed clinical, biochemical, neuroimaging (resting functional MRI, structural MRI, diffusion tensor imaging and magnetic resonance spectroscopy) and genetic assessments (genome-wide association studies, whole-genome sequencing (WGS)) are performed every 2 years in each participant.

A parallel study - the Srinivaspura Aging, Neuro Senescence and COGnition (SANSCOG) study - is being conducted in rural India, that is in the villages of Srinivaspura taluk (states are divided into districts and districts are subdivided into taluks) in the state of Karnataka in southern India ${ }^{98}$. The SANSCOG study began in 2018 and comprises individuals from an

\section{The role of vascular dysfunction}

As discussed, the prevalence of hypertension and cardiovascular disease in India is growing. Therefore, understanding the link between vascular dysfunction and dementia risk in this population is essential. In particular, we urgently need a better understanding of how the cerebral vasculature is affected following small infarcts and microbleeds, and the point at which this accumulating cerebrovascular burden translates to the clinical manifestations of dementia. MRI offers an unparalleled opportunity to study disease progression in the brain in a non-invasive manner. In brain MRI, ischaemia of cerebral small vessels is prominently seen as white matter hyperintensities ${ }^{103}$, which in turn have been shown to be associated with poor cognitive function $^{104,105}$. Longitudinal, quantitative MRI measurements of periventricular and deep white matter hyperintensities might help us understand the role they have in ageing and cognitive decline. Therefore, longitudinal studies in ageing cohorts from India should include MRI as a key component to understand the changes in white matter hyperintensity volume and 
distribution that occur in cognitively healthy ageing as well as in dementia. Another important goal of this future research should be to determine quantitatively, whether white matter hyperintensity load in the Indian population is different from that in North American and European populations. Vascular risk factors might not be the only contributors to cerebrovascular dysfunction - the potential effects of genetic risk factors, life events and other environmental components should also be considered, particularly with regard to dysfunction of small vessels. MRI studies of these microvascular and structural changes in the population of India will be of immense clinical significance.

Future dementia research in India should also focus on understanding the interplay between cerebrovascular dysfunction, amyloid accumulation and hyperphosphorylation of tau, all of which contribute to cognitive dysfunction in older individuals ${ }^{106-108}$. However, in our experience, performing PET imaging of $\mathrm{A} \beta$ and phosphorylated tau ( $\mathrm{p}$-tau) in India can be challenging owing to limited availability of PET ligands. Therefore, the potential use of peripheral blood biomarkers such as, $\mathrm{A} \beta_{1-40}, \mathrm{~A} \beta_{1-42}$, p-tau, total tau and neurofilament light chain, should be examined. Some international studies into the associations between cerebrovascular disease and neurodegenerative diseases have been performed using animal models ${ }^{109,110}$. Nevertheless, in our opinion, the substantial increase in the prevalence of vascular risk factors, the complex sociocultural milieu and exposure to pollutants means that India should be a specific focus of such research.

\section{Ongoing genetic studies}

Genetic studies, particularly WGS and cataloguing of genetic diversity, in India are lacking. In the 1000 Genomes project ${ }^{111}$ (resource now accessible through the International Genome Sample Resource), only 243 out of a total of 3,202 participants are of Indian origin. Another resource (namely, the Genome Aggregation Database (gnomAD)) has only 2,419 genomes of South Asian ancestry including India out of 76,156 genomes. India has great genetic diversity owing to several waves of migration from Africa, the Middle East, and central and northern Europe and the subsequent admixture ${ }^{112}$. The caste system and resultant endogamy also contribute to a unique genetic landscape $\mathrm{e}^{112}$.

To begin to understand the landscape of genetic risk of dementia in the Indian population, the LASI-DAD study included a microarray-based analysis of 56 single-nucleotide polymorphisms known to be associated with $\mathrm{AD}$ risk in populations of European ancestry. The results of that analysis indicated that the genetic risks seen in people of European ancestry have only a limited role in the Indian population, highlighting the need for more comprehensive studies of the genetic architecture in India ${ }^{113}$. Against this backdrop, a large project, GenomeIndia, was recently launched with the aim of performing WGS in a cohort of 10,000 people from India to produce a catalogue of genetic variations. This project, funded by the Department of Biotechnology, Government of India, is the first of its kind in this region, brings together researchers from 20 institutions across
India and is the first step towards building a national genetic resource. The GenomeIndia project aims to assemble a cohort of unrelated individuals sampled from well-defined ethnic groups that are largely representative of the spectrum of genetic diversity of the Indian population. The sampling strategy is based on a grid that represents the ethnicity of population groups, their geographical spread, linguistic preferences, and size according to the most recent census data. This sampling is a complex task as the population of India consists of $\sim 1.3$ billion people and $>300$ prominent spoken languages, and can be stratified into $\sim 4,600$ population groups comprising multiple endogamous subgroups ${ }^{114}$.

\section{Interventions}

Given the increasing prevalence of risk factors of vascular dysfunction in India, one of the most cost-effective ways of addressing the challenge of dementia in India might be to mitigate this vascular risk by putting in place appropriate public health intervention strategies at mid-life or earlier. For example, evidence from studies performed in other regions suggests that controlling hypertension is the single most important factor in reducing the risk of both cardiovascular and cerebrovascular diseases ${ }^{115,116}$. Evidence also indicates that the South Asian population has a higher genetic risk of metabolic syndrome and cardiovascular disease than populations of European ancestry ${ }^{117}$. Therefore, the cut-offs for early diagnosis of vascular risk factors might need to be adapted to the relevant geographical region or ethnic group.

Any public health interventions intended for use in India must be developed with the understanding that universal health care is not available and that large sections of the population have a low income. For this reason, and owing to India's unique sociocultural milieu, interventions performed in Europe and the USA cannot be directly translated. For example, tobacco cessation programmes in India should address not only cigarette smoking, which has been the focus of such programmes in Europe and the USA, but also other forms of tobacco intake such as chewing tobacco and using nasal snuff. Indeed, in India, use of smokeless tobacco is not only the single largest risk factor for head and neck cancer ${ }^{118}$ but is also expected to affect dementia incidence. Similarly, dietary recommendations such as the Mediterranean diet, which involves high intake of fruits, nuts, fish and olive oil, are likely to be challenging to implement in India as these foods would not be accessible or affordable for many people. Indeed, the majority of the Indian population have a high carbohydrate diet, mainly comprising rice, wheat or millets ${ }^{119}$. Therefore, public health interventions for dementia prevention need to be adapted and performed in a manner that is culturally acceptable and economically viable. Any interventions intended for use in the Indian population should be tested in well-designed, controlled clinical trials to establish their efficacy, inform public health policy and facilitate translation to the Indian primary health-care system.

Multimodal lifestyle interventions have been shown to delay the onset and/or progression of dementia as demonstrated by the Finnish Geriatric Intervention 
Study to Prevent Cognitive Impairment and Disability (FINGER) trial ${ }^{120}$, which is now being replicated in several parts of the world ${ }^{121}$. This study has shown that a combination of a Mediterranean-style diet, structured, rigorous exercises and cognitive training can reduce the onset of dementia by 2 years. To implement such a study in South Asian countries, particularly India, considerable iteration and experimentation is required to formulate equivalent components. The recommended diet should be similar in nutritional composition to the Mediterranean-style diet but more suited to the Indian palate and comprising foods that are locally grown or easily available. Similarly, rigorous exercises, such as aerobics might not be acceptable to the elderly population in India, who would prefer gentler exercises such as walking or yoga. Therefore, exercise paradigms that incorporate such methods would be acceptable and more easily implementable. Cognitive training also needs to be implemented in a culturally acceptable manner, especially considering the rural population in India with low levels of literacy. Examining the role of mindfulness-based interventions and contemplative practices would be worthwhile as these would be culturally adaptable and easily scalable. Once the proof-of-concept of these tailored strategies has been robustly demonstrated, they will need to be scaled-up to provide larger public health interventions. In our opinion, such preventive public health measures would be the appropriate approach to lower the growing burden of dementia in LMICs including India. This would be the most cost-effective strategy, as structured dementia care facilities in India are scarce and the cost of care is prohibitive to large portions of the population ${ }^{122}$.

\section{Perspective and conclusion}

With rapidly changing demographic patterns and increasing prevalence of vascular dysfunction, the prevalence of dementia in India is expected to increase at an alarming rate. Well-planned, harmonized and large-scale studies of dementia epidemiology, genetics, risk factors and protective factors are urgently needed in this region. As the role of vascular risk factors in dementia is becoming increasingly evident, understanding the complex mechanisms by which these factors contribute to dementia aetiopathogenesis will aid the development of public health measures to address these risks at an early stage. Dementia is complex, so the use of scalable public health interventions throughout the life course will be important. There is a need to differentiate early-onset dementia ( $<60$ years of age) and late-onset dementia ( $>60$ years of age). Research needs to be tailored towards translation to public health interventions, as community-based methods have greater impact than individualized clinic-based approaches ${ }^{123}$.

As longitudinal and intervention studies begin and progress in India, an important focus should be the harmonization of protocols with those previously used in North America and Europe. This harmonization will be helpful on two fronts. First, it will capitalize on and add to our existing knowledge, as dementia research expands into newer territories. Second, comparison of data obtained from different countries and continents could yield valuable insights into the pathogenesis and progression of dementia from diverse populations, thus enabling extrapolation of information to similar populations around the world. Data sharing will be an essential part of this process and would be particularly valuable for LMICs including India, where it could reduce research costs and enable more meaningful insights to be gained from existing data. In our opinion, South Asian countries, such as India, that have only recently invested in dementia research would also benefit from becoming part of global consortia such as the Alzheimer's Disease Neuroimaging Initiative and the World-Wide FINGERS network. Being part of such consortia would provide access to state-of-the-art technology to facilitate use of new methodologies, capacity building and bidirectional data sharing.

In conclusion, the need of the hour is to harmonize studies and organize data in federated databases to enable sharing and analysis by the global dementia research community. Such initiatives would yield a combined wealth of information on healthy and pathological ageing, which could aid the development of strategies to prevent or delay the onset of dementia through community-based interventions at the primary care level.

Published online 18 October 2021
1. Cantarero-Prieto, D., Leon, P. L., Blazquez-Fernandez, C., Juan, P. S. \& Cobo, C. S. The economic cost of dementia: a systematic review. Dementia 19 2637-2657 (2019).

2. World Health Organization. Dementia (WHO, 2021). Provides basic facts on dementia, including prevalence, symptoms, forms, treatment and impact.

3. Leroi, I. et al. A roadmap to develop dementia research capacity and capability in Pakistan: a model for low- and middle-income countries. Alzheimers Dement. 5, 939-952 (2019).

4. Kalaria, R. N. et al. Alzheimer's disease and vascular dementia in developing countries: prevalence, management, and risk factors. Lancet Neurol. 7 812-826 (2008)

5. Hunter, D. J. \& Reddy, K. S. Noncommunicable diseases. N. Engl. J. Med. 369, 1336-1343 (2013).

6. Misra, A. Diabetes, cardiovascular disease, and chronic kidney disease in South Asia: current status and future directions. BMJ 357, j1420 (2017).

7. India State-Level Disease Burden Initiative Collaborators. Nations within a nation: variations in epidemiological transition across the states of India, $1990-2016$ in the Global Burden of Disease Study. Lancet 390, 2437-2460 (2017).

Highlights the epidemiological transition in India from communicable diseases to non-communicable diseases as well as the unequal disease burden between different states within India.

8. Arokiasamy, P. India's escalating burden of non-communicable diseases. Lancet Glob. Health 6, 1262-1263 (2018)

9. United Nations, Department of Economic and Social Affairs, Population Division. World population ageing (UN, 2017).

Brings to light the changing trends in demography across the world, wherein a rapid and unprecedented increase in the number and proportion of older persons is taking place, especially in South Asia.

10. Office of the Registrar General \& Census Commissioner India. Population enumeration data (final population). Census India https://censusindia.gov.in/2011 census/ population_enumeration.html (2011).

11. Alzheimer's Disease International. World Alzheimer report 2015: the global impact of dementia (ADI, 2015)
12. Mouches, P., Langner, S., Domin, M., Hill, M. D. \& Forkert, N. D. Influence of cardiovascular risk-factors on morphological changes of cerebral arteries in healthy adults across the life span. Sci. Rep. 11, 12236 (2021).

13. International Diabetes Federation. IDF Diabetes Atlas 9 th edn (International Diabetes Federation, 2019).

14. International Institute for Population Sciences $\&$ Ministry of Health and Family Welfare. Key indicators: 22 states/UTs from phase-I. National Family Health Survey (NFHS-5) 2019-20 (IIPS, 2020).

15. Gupta, R., Gaur, K. \& Ram, C. V. S. Emerging trends in hypertension epidemiology in India. J. Hum. Hypertens. 33, 575-587 (2019).

16. Anchala, R. et al. Hypertension in India: a systematic review and meta-analysis of prevalence, awareness, and control of hypertension. J. Hypertens. 32, 1170-1177 (2014)

17. Claypool, K. T., Chung, M. K., Deonarine, A. Gregg, E. W. \& Patel, C. J. Characteristics of undiagnosed diabetes in men and women under the age of 50 years in the Indian subcontinent: The National Family Health Survey (NFHS-4)/Demographic Health Survey 2015-2016. BMJ Open Diabetes Res. Care 8, e000965 (2020) 
18. Prenissl, J. et al. Hypertension screening, awareness, treatment, and control in india: a nationally representative cross-sectional study among individuals aged 15 to 49 years. PLoS Med. 16, e 1002801 (2019).

19. Prenissl, J. et al. Variation in health system performance for managing diabetes among states in India: a cross-sectional study of individuals aged 15 to 49 years. BMC Med. 17, 92 (2019).

20. Patel, V. et al. Chronic diseases and injuries in India. Lancet 377, 413-428 (2011).

21. Institute for Health Metrics and Evaluation. GBD compare. Viz Hub https://vizhub. healthdata.org/ gbd-compare/ (2019).

22. Ministry of Statistics and Programme Implementation, Central Statistics Office. India in figures 2018 (MOSPI, 2018).

23. GBD Dementia Collaborators. Global, regional, and national burden of Alzheimer's disease and other dementias, 1990-2016: a systematic analysis for the Global Burden of Disease Study 2016. Lancet Neurol. 18, 88-106 (2019)

24. Mathew, R. \& Mathuranath, P. Issues in evaluation of cognition in the elderly in developing countries. Ann. Indian Acad. Neurol. 11, 82-88 (2008)

25. Mekala, S. et al. Dementia diagnosis in seven languages: the Addenbrooke's cognitive examination-II in India. Arch. Clin. Neuropsychol. 35, 528-538 (2020).

26. lyer, G. K. et al. Standardising dementia diagnosis across linguistic and educational diversity: study design of the indian council of medical research-neurocognitive tool box (ICMR-NCTB). J. Int. Neuropsychol. Soc. 26, 172-186 (2020).

27. Chandra, V. et al. Prevalence of Alzheimer's disease and other dementias in rural India: the Indo-US study. Neurology 51, 1000-1008 (1998).

28. Rodriguez, J. J. L. et al. Prevalence of dementia in Latin America, India, and China: a population-based cross-sectional survey. Lancet 372, 464-474 (2008)

29. Prince, M. et al. Dementia diagnosis in developing countries: a cross-cultural validation study. Lancet 361, 909-917 (2003).

30. Das, S. K. et al. A random sample survey for prevalence of major neurological disorders in Kolkata. Indian J. Med. Res. 124, 163-172 (2006).

31. Banerjee, T. K. et al. Epidemiology of dementia and its burden in the city of Kolkata, India. Int. J. Geriatr. Psychiatry 32, 605-614 (2017).

32. Raina, S. K. et al. Identifying risk for dementia across populations: a study on the prevalence of dementia in tribal elderly population of Himalayan region in Northern India. Ann. Indian Acad. Neurol. 16, 640-644 (2013)

33. Rajkumar, S., Kumar, S. \& Thara, R. Prevalence of dementia in a rural setting: a report from India. Int. J. Geriatr. Psychiatry 12, 702-707 (1997).

34. Rajkumar, S. \& Kumar, S. Prevalence of dementia in the community: a rural-urban comparison from Madras, India. Aust. J. Ageing 15, 57-61 (1996).

35. Avlund, K., Luck, M. \& Tinsley, R. Cultural differences in functional ability among elderly people in Birmingham, England, and Glostrup, Denmark J. Cross Cult. Gerontol. 11, 1-16 (1996).

36. Kumar, C. T. S., Shaji, K. S., Varghese, M. ¿ Nair, M. K. C. (eds) Dementia in India 2020 (Alzheimer's and Related Disorders Society of India, 2019)

37. Ryan, N. \& Fox, N. Imaging presymptomatic Alzheimer's disease. Adv. Clin. Neurosci. Rehabil. 14, 6-9 (2014)

38. Boyle, P. A. et al. Person-specific contribution of neuropathologies to cognitive loss in old age. Ann. Neurol. 83, 74-83 (2018).

39. Scott, T. M., Bhadelia, R. A., Qiu, W. Q., Folstein, M. F. $\&$ Rosenberg, I. H. Small vessel cerebrovascular pathology identified by magnetic resonance imaging is prevalent in Alzheimer's disease and mild cognitive impairment: a potential target for intervention. J. Alzheimers Dis. 65, 293-302 (2018). Shows the important role of cerebrovascular pathology, particularly small vessel disease, in people diagnosed with $A D$.

40. Matthews, F. E. et al. Epidemiological pathology of dementia: attributable-risks at death in the Medical Research Council Cognitive Function and Ageing Study. PLoS Med. 6, e1000180 (2009).

41. de Bruijn, R. F. \& Ikram, M. A. Cardiovascular risk factors and future risk of Alzheimer's disease. BMC Med. 12, 130 (2014).

42. Leritz, E. C., McGlinchey, R. E., Kellison, I., Rudolph, J. L. $\&$ Milberg, W. P. Cardiovascular disease risk factors and cognition in the elderly. Curr. Cardiovasc. Risk Rep. 5 407-412 (2011).

43. India State-Level Disease Burden Initiative C V D Collaborators. The changing patterns of cardiovascular diseases and their risk factors in the states of India: the Global Burden of Disease Study 1990-2016. Lancet Glob. Health 6 e 1339-e1351 (2018).

44. Lee, J. et al. Design and methodology of the Longitudinal Aging Study in India-Diagnosti Assessment of Dementia (LASI-DAD). J. Am. Geriatr. Soc. 68 (Suppl. 3), 5-10 (2020).

45. Farron, M. R. et al. Hypertension and cognitive health among older adults in India. J. Am. Geriatr. Soc. 68 (Suppl. 3), 29-35 (2020).

46. Hu, P. et al. Cognitive function and cardiometabolicinflammatory risk factors among older Indians and Americans. J. Am. Geriatr. Soc. 68 (Suppl. 3), 36-44 (2020).

47. Prabhakaran, D. et al. Cardiovascular diseases in india compared with the United States. J. Am. Coll. Cardiol. 72, 79-95 (2018).

Compares the burden of cardiovascular diseases in India and the USA

48. Chuang, Y. F. et al. Midlife adiposity predicts earlier onset of Alzheimer's dementia, neuropathology and presymptomatic cerebral amyloid accumulation. Mol. Psychiatry 21, 910-915 (2016)

49. Zheng, F., Yan, L., Yang, Z., Zhong, B. \& Xie, W. $\mathrm{HbA} 1 \mathrm{c}$, diabetes and cognitive decline: the English Longitudinal Study of Ageing. Diabetologia 61 839-848 (2018)

50. Buss, S. et al. Objective cardiac markers in dementia: results from the Kerala-Einstein study. Int. J. Cardiol. 167, 595-596 (2013).

51. Agrawal, A., Aggarwal, M., Sonnappa, S. \& Bush, A. Ethnicity and spirometric indices: hostage to tunne vision? Lancet Respir. Med. 7, 743-744 (2019).

52. Arcari, A. et al. Relation between pulmonary function and 10-year risk for cardiovascular disease among healthy men and women in Italy: the Moli-sani Project. Eur. J. Prev. Cardiol. 20, 862-871 (2013).

53. Ramalho, S. H. R. \& Shah, A. M. Lung function and cardiovascular disease: a link. Trends Cardiovasc. Med. 31, 93-98 (2021).

54. Kim, J., Basak, J. M. \& Holtzman, D. M. The role of apolipoprotein $\mathrm{E}$ in Alzheimer's disease. Neuron 63 287-303 (2009)

Discusses the role of APOE as an important genetic risk factor for $A D$

55. Ganguli, M. et al. Apolipoprotein E polymorphism and Alzheimer disease: the Indo-US cross-national dementia study. Arch. Neurol. 57, 824-830 (2000).

56. Bharath, S. et al. Apolipoprotein E polymorphism and dementia: a hospital-based study from southern India. Dement. Geriatr. Cogn. Disord. 30, 455-460 (2011).

57. Chandak, G. R., Sridevi, M. U., Vas, C. J., Panikker, D. M. \& Singh, L. Apolipoprotein E and presenilin-1 allelic variation and Alzheimer's disease in India. Hum. Biol. 74, 683-693 (2002).

58. Luthra, K. et al. Apolipoprotein E gene polymorphism in Indian patients with Alzheimer's disease and vascular dementia. Dement. Geriatr. Cogn. Disord. 17, 132-135 (2004)

59. Kapur, S., Sharad, S., Kapoor, M. \& Bala, K. ApoE genotypes: risk factor for Alzheimer's disease. J. Indian Acad. Clin. Med. 7, 118-122 (2006).

60. Pandey, P., Pradhan, S. \& Mittal, B. Presenilin gene predisposes to late-onset degenerative but not vascular dementia: a comparative study of PS1 and ApoE genes in a North Indian Cohort. Dement. Geriatr Cogn. Disord. 24, 151-161 (2007)

61. Sánchez, L. et al. Variation in the LRP-associated protein gene (LRPAP1) is associated with late-onset Alzheimer disease. Am. J. Med. Genet. 105, 76-78 (2001).

62. Pandey, P., Pradhan, S. \& Mittal, B. LRP-associated protein gene (LRPAP1) and susceptibility to degenerative dementia. Genes Brain Behav. 7 943-950 (2008)

63. Mansoori, N. et al. IL-6-174 G/C and ApoE gene polymorphisms in Alzheimer's and vascular dementia patients attending the cognitive disorder clinic of the All India Institute of Medical Sciences, New Delhi. Dement. Geriatr. Cogn. Disord. 30, 461-468 (2010)

64. Ghosh, T. et al. A preliminary study on the influence of glutathione S transferase T1 (CSTT1) as a risk factor for late onset Alzheimer's disease in North Indian population. Asian J. Psychiatr. 5, 160-163 (2012).

65. Alam, R. et al. Synergistic epistasis of paraoxonase 1 (rs662 and rs85460) and apolipoprotein E4 genes in pathogenesis of Alzheimer's disease and vascular dementia. Am. J. Alzheimers Dis. Other Demen. 29, 769-776 (2014).

66. Jairani, P. S., Aswathy, P. M., Gopala, S., Verghese, J. $\&$ Mathuranath, P. S. Interaction with the MAPT $\mathrm{H} 1 \mathrm{H} 1$ genotype increases dementia risk in APOE $\varepsilon 4$ carriers in a population of southern India. Dement. Geriatr. Cogn. Disord. 42, 255-264 (2016).

67. Ferretti, M. T. et al. Sex differences in Alzheimer disease-the gateway to precision medicine. Nat. Rev. Neurol. 14, 457-469 (2018).

This review explores the evidence for sex differences in the patterns of manifestation, progression and brain pathology in AD.

68. Nebel, R. A. et al. Understanding the impact of sex and gender in Alzheimer's disease: a call to action. Alzheimers Dement. 14, 1171-1183 (2018).

69. Kenchappa, R. S., Diwakar, L., Annepu, J. \& Ravindranath, V. Estrogen and neuroprotection: higher constitutive expression of glutaredoxin in female mice offers protection against MPTP-mediated neurodegeneration. FASEB J. 18, 1102-1104 (2004).

70. Diwakar, L. et al. Down-regulation of glutaredoxin by estrogen receptor antagonist renders female mice susceptible to excitatory amino acid mediated complex I inhibition in CNS. Brain Res. 1125 , 176-184 (2006).

71. Geldsetzer, P. et al. Geographic and sociodemographic variation of cardiovascular disease risk in India: a cross-sectional study of 797,540 adults. PLoS Med. 15, e1002581 (2018).

72. Huffman, M. D. et al. Incidence of cardiovascular risk factors in an Indian urban cohort. J. Am. Coll. Cardiol. 57, 1765-1774 (2011)

73. Pande, R. P. Selective gender differences in childhood nutrition and immunization in rural India: the role of siblings. Demography 40, 395-418 (2003).

74. Corsi, D. J., Mejia-Guevara, I. \& Subramanian, S. V. Risk factors for chronic undernutrition among children in India: estimating relative importance, population attributable risk and fractions. Soc. Sci. Med. 157 165-185 (2016)

75. Angrisani, M., Jain, U. \& Lee, J. Sex differences in cognitive health among older adults in India. J. Am. Geriatr. Soc. 68, 20-28 (2020).

76. Hoogendijk, E. O. et al. The Longitudinal Aging Study Amsterdam: cohort update 2016 and major findings. Eur. J. Epidemiol. 31, 927-945 (2016).

77. Marden, J. R., Tchetgen Tchetgen, E. J., Kawachi, I. \& Glymour, M. M. Contribution of socioeconomic status at 3 life-course periods to late-life memory function and decline: early and late predictors of dementia risk. Am. J. Epidemiol. 186, 805-814 (2017).

78. Wu, Y. T. et al. Education and wealth inequalities in healthy ageing in eight harmonised cohorts in the ATHLOS consortium: a population-based study. Lancet Public Health 5, e386-e394 (2020).

79. Cadar, D et al. Individual and area-based socioeconomic factors associated with dementia incidence in England: evidence from a 12-year follow-up in the English Longitudinal Study of Ageing. JAMA Psychiatry 75, 723-732 (2018).

80. Hoogendijk, E. O., Heymans, M. W., Deeg, D. J. H. \& Huisman, M. Socioeconomic inequalities in frailty among older adults: results from a 10-year longitudinal study in the Netherlands. Gerontology 64, 157-164 (2018)

81. Dugravot, A. et al. Social inequalities in multimorbidity, frailty, disability, and transitions to mortality: a 24-year follow-up of the Whitehall II cohort study. Lancet Public Health 5, 42-50 (2020).

82. Barnett, K. et al. Epidemiology of multimorbidity and implications for health care, research, and medical education: a cross-sectional study. Lancet 380, 37-43 (2012).

83. Nitrini, R. et al. Prevalence of dementia in Latin America: a collaborative study of population-based cohorts. Int. Psychogeriatr. 21, 622-630 (2009).

84. Bialystok, E., Craik, F. I. M. \& Freedman, M. Bilingualism as a protection against the onset of symptoms of dementia. Neuropsychologia 45 , 459-464 (2007).

85. Alladi, S. et al. Bilingualism delays age at onset of dementia, independent of education and immigration status. Neurology 81, 1938-1944 (2013).

86. Alladi, S. et al. Bilingualism delays the onset of behavioral but not aphasic forms of frontotemporal dementia. Neuropsychologia 99, 207-212 (2017).

87. Dhillon, P., Ladusingh, L. \& Agrawal, G. Ageing and changing patterns in familial structure for older persons in India: a decomposition analysis. Qual. Ageing Older Adults 17, 83-96 (2016). 
88. Mahalle, N., Kulkarni, M. V., Garg, M. K. \& Naik, S. S Vitamin B12 deficiency and hyperhomocysteinemia as correlates of cardiovascular risk factors in Indian subjects with coronary artery disease. J. Cardiol. 61 289-294 (2013)

89. Seshadri, S. et al. Plasma homocysteine as a risk factor for dementia and Alzheimer's disease. N. Engl. J. Med. 346, 476-483 (2002).

90. Goodwill, A. M. \& Szoeke, C. A systematic review and meta-analysis of the effect of low vitamin $D$ on cognition. J. Am. Geriatr. Soc. 65, 2161-2168 (2017).

91. Mechenro, J., Venugopal, G., Kumar, M. B., Balakrishnan, D. \& Ramakrishna, B. S. Vitamin D status in Kancheepuram District, Tamil Nadu. BMC Public Health 18, 1345 (2018).

92. Suryanarayana, P. et al. Prevalence of vitamin $D$ deficiency and its associated factors among the urban elderly population in Hyderabad metropolitan city, South India. Ann. Hum. Biol. 45, 133-139 (2018).

93. Office of the Registrar General \& Census Commissioner Provisional population totals: paper 2, volume 1 of 2011, rural-urban distribution, India series 1. Census India https://censusindia.gov.in/2011-prov-results/ paper2/prov_results_paper2_india.html (2011).

94. Banerjee, S. Determinants of rural-urban differential in healthcare utilization among the elderly population in India. BMC Public Health 21, 939 (2021) Reveals the gap in healthcare utilization between rural and urban older persons in India and explores the determinants of this difference.

95. Barik, D. \& Thorat, A. Issues of unequal access to public health in India. Front. Public Health 3, 245 (2015).

96. Nitika, Lohiya, A., Nongkynrih, B. \& Gupta, S. K. Migrants to urban India: need for public health action. Indian J. Community Med. 39, 73-75 (2014).

97. Abhishek, M. L., Balakrishnan, A., Muralidhar, S. D., Rao, N. P. \& Ravindranath, V. Relation between CAIDE scores and cognition: data from TATA Longitudinal Study of Ageing. Alzheimers Dement. 16, e045700 (2020).

98. Sundarakumar, J. et al. Srinivaspura Aging, Neuro Senescence and COGnition (SANSCOG) study and Tata Longitudinal Study on Aging (TLSA): study protocols. Alzheimers Dement. 16, e045681 (2020).

99. Ritchie, K et al. COGNITO: computerized assessment of information processing. J. Psychol. Psychother. 4 , 136 (2014).

100. Sundarakumar, J., Sivakumar, P. T., Rao, N. P. \& Ravindranath, V., SANSCOG and TLSA Investigators. Comparison of obesity, diabetes, hypertension and depression in two parallel, aging study cohorts from rural and urban India: SANSCOG study and TLSA. Alzheimers Dement. 16, e045711 (2020).

101. Tiwari, V. et al. MRI investigations of white matter hyperintensity and structural abnormalities of brain in urban and rural cohorts of India. Alzheimers Dement. 16, e045687 (2020)

102. Alladi, S. AADAR Dementia Science Research Group India AADAR Dementia Science Program: methodology of a longitudinal multicentric and multidisciplinary commitment from India for epidemiology, clinical case registry and basic science research on dementia and related disorders [abstract P2-524]. Alzheimers Dement. 15 (Suppl. 7), 818-819 (2019).

103. Hajiar, I. et al. Hypertension, white matter hyperintensities, and concurrent impairments in mobility, cognition, and mood: the Cardiovascular Health Study. Circulation 123, 858-865 (2011).

104. Whitman, G. T., Tang, Y., Lin, A. \& Baloh, R. W. A prospective study of cerebral white matter abnormalities in older people with gait dysfunction. Neurology 57, 990-994 (2001).

105. Prins, N. D. \& Scheltens, P. White matter hyperintensities, cognitive impairment and dementia: an update. Nat. Rev. Neurol. 11, 157-165 (2015).
106. Köbe, T. et al. Association of vascular risk factors with $\beta$-amyloid peptide and tau burdens in cognitively unimpaired individuals and its interaction with vascular medication use. JAMA Netw. Open 3, e1920780 (2020).

Findings point to the complex interplay between vascular risk factors and brain $A \beta$ burden.

107. Mattsson, N. et al. Association of brain amyloid- $\beta$ with cerebral perfusion and structure in Alzheimer's disease and mild cognitive impairment. Brain J. Neurol. 137, 1550-1561 (2014).

108. Albrecht, D. et al. Associations between vascular function and tau PET are associated with global cognition and amyloid. J. Neurosci. 40, 8573-8586 (2020).

109. Li, H. et al. Vascular and parenchymal amyloid pathology in an Alzheimer disease knock-in mouse model: interplay with cerebral blood flow. Mol. Neurodegener. 9, 28 (2014)

110. Lendahl, U., Nilsson, P. \& Betsholtz, C. Emerging links between cerebrovascular and neurodegenerative diseases-a special role for pericytes. EMBO Rep. 20 , e48070 (2019)

111. 1000 Genomes Project Consortium. et al.An integrated map of genetic variation from 1,092 human genomes. Nature 491, 56-65 (2012).

112. Basu, A., Sarkar-Roy, N. \& Majumder, P. P. Genomic reconstruction of the history of extant populations of India reveals five distinct ancestral components and a complex structure. Proc. Natl Acad. Sci. USA 113 1594-1599 (2016).

113. Smith, J. A. et al. Association between episodic memory and genetic risk Factors for Alzheimer's disease in South Asians from the Longitudinal Aging Study in India-Diagnostic Assessment of Dementia (LASI-DAD). J. Am. Geriatr. Soc. 68 (Suppl. 3), 45-53 (2020).

114. Singh, K. S. People of India: Introduction Anthropological Survey of India (Oxford Univ. Press, 2002).

115. Ettehad, D. et al. Blood pressure lowering for prevention of cardiovascular disease and death: a systematic review and meta-analysis. Lancet 387 , 957-967 (2016).

116. Gaciong, Z., Siński, M. \& Lewandowski, J. Blood pressure control and primary prevention of stroke: summary of the recent clinical trial data and meta-analyses. Curr. Hypertens. Rep. 15, 559-574 (2013).

117. Pandit, K., Goswami, S., Ghosh, S., Mukhopadhyay, P. $\&$ Chowdhury, S. Metabolic syndrome in South Asians. Indian J. Endocrinol. Metab. 16, 44-55 (2012).

118. Boffetta, P., Hecht, S., Gray, N., Gupta, P. \& Straif, K Smokeless tobacco and cancer. Lancet Oncol. 9, 667-675 (2008).

119. Joshi, S. R. et al. Results from a dietary survey in an Indian T2DM population: a STARCH study. BMJ Open 4, e005138 (2014)

120. Ngandu, T. et al. A 2 year multidomain intervention of diet, exercise, cognitive training, and vascular risk monitoring versus control to prevent cognitive decline in at-risk elderly people (FINGER): a randomised controlled trial. Lancet 385, 2255-2263 (2015). A large-scale, randomised controlled trial that demonstrated the effectiveness of multidomain interventions in improving cognitive functioning in older persons at risk of cognitive impairment.

121. Kivipelto, M. et al. World-Wide FINGERS Network: a global approach to risk reduction and prevention of dementia. Alzheimers Dement. 16, 1078-1094 (2020).

122. Rao, G. N. \& Bharath, S. Cost of dementia care in India: delusion or reality? Indian J. Public Health 57, 71-77 (2013)

123. Zulman, D. M., Vijan, S., Omenn, G. S. \& Hayward, R. A The relative merits of population-based and targeted prevention strategies. Milbank 0 , 86, 557-580

(2008).

124. Shaji, S., Promodu, K., Abraham, T., Roy, K. J. \& Verghese, A. An epidemiological study of dementia in a rural community in Kerala, India. Br. J. Psychiatry 168, 745-749 (1996)

125. Raina, S., Razdan, S., Pandita, K. \& Raina, S. Prevalence of dementia among Kashmiri migrants. Ann. Indian Acad. Neurol. 11, 106-108 (2008)

126. Raina, S. K., Razdan, S. \& Pandita, K. K. Prevalence of dementia in ethnic Dogra population of Jammu district, North India: a comparison survey. Neurol. Asia 15, 65-69 (2010).

127. Rao, T. S. S. Suttur study: an epidemiological study of psychiatric disorders in south Indian rural population Indian J. Psychiatry 56, 238-245 (2014).

128. Vas, C. J. Prevalence of dementia in an urban Indian population. Int. Psychogeriatr. 13, 439-450 (2001).

129. Shaji, S., Bose, S. \& Verghese, A. Prevalence of dementia in an urban population in Kerala, India. Br. J. Psychiatry 186, 136-140 (2005).

130. Mathuranath, P. S. Dementia in Kerala, South India: prevalence and influence of age, education and gender. Int. J. Geriatr. Psychiatry 25, 290-297 (2010)

131. Saldanha, D., Mani, M. R., Srivastava, K., Goyal, S. $\&$ Bhattacharya, D. An epidemiological study of dementia under the aegis of mental health program, Maharashtra, Pune chapter. Indian J. Psychiatry 52, 131-139 (2010)

\section{Acknowledgements}

We acknowledge Tata Trusts for funding TLSA and Pratiksha Trust, the philanthropy arm of K. Gopalakrishnan for funding the SANSCOG study through the Centre for Brain Research. We thank B. Kahali, A.L. Menesgere, V. Tiwari and S.K.S. Hameed for their help in preparing the manuscript. We also thank all our study subjects for their participation and kind cooperation.

\section{Author contributions}

All authors contributed equally.

Competing interests

The authors declare no competing interests.

Peer review information

Nature Reviews Neurology thanks K. Anstey, C. Brayne and the other anonymous, reviewer(s) for their contribution to the peer review of this work.

\section{Publisher's note}

Springer Nature remains neutral with regard to jurisdictional claims in published maps and institutional affiliations.

\section{Research criteria}

We searched PubMed for English language studies published between 1995 and 2020. Search terms included "dementia", "Alzheimer's disease", "mild cognitive impairment" "prevalence", "epidemiology" and "survey", with respect to studies conducted in India. Although no formal quality assessment was undertaken, we only included studies that had proper case definitions and clearly defined study populations. We also reviewed official reports of the Indian government and national-level expert bodies as well as surveys using nationally representative data.

\section{RELATED LINKS \\ Alzheimer's Disease Neuroimaging Initiative: http://adni. \\ Genome Aggregation Database (gnomAD): https://gnomad. broadinstitute.org/ \\ International Genome Sample Resource: https://www. \\ internationalgenome.org/ \\ World-Wide FINGERS network: https://wwfingers.com/}

(c) Springer Nature Limited 2021 